\title{
The subtle politics of organ donation: a proposal
}

\author{
Stephanie Eaton University of Edinburgh, Edinburgh
}

\begin{abstract}
Organs available for transplantation are scarce and valuable medical resources and decisions about who is to receive them should not be made more difficult by complicated calculations of desert. Consideration of likely clinical outcome must always take priority when allocating such a precious resource otherwise there is a danger of wasting that resource. However, desert may be a relevant concern in decision-making where the clinical risk is identical between two or more potential recipients of organs. Unlikely as this scenario is, such a decision procedure makes clear the interdependence of organ recipient and organ donor and hints at potential disadvantages for those who are willing to accept but unwilling to donate organs (free-riders). A combined opting-out and preference system weakens many of the objections to opting-out systems and may make the decision to donate organs on behalf of their deceased relatives easier for families.

(Fournal of Medical Ethics 1998;24:166-170)
\end{abstract}

Keywords: Organ donation; free-riding; opting out

\section{Inferring the wishes of donors}

The system for potential organ donor recruitment in the UK operates such that persons indicate willingness to be an organ donor by the carrying of a donor card or the completion of a section of the driver's licence; it is also possible to express consent in what is known as a "living will". Such a system of opting-in through donor cards etc gives a firm indication of the deceased's views but is inadequate because of low public participation in the scheme. The Human Tissue Act 1961 requires that relatives be consulted about organ donation in the absence of any indication from the deceased. Where there is no evidence of consent, families may be called upon to make decisions at a difficult time without certain knowledge of the prior views of the deceased. Without such knowledge, families are often reluctant to give permission for organ donation; understandably hospitals do not wish to seem coercive at times of grief and as a result potential organs are lost.

As is well known, some countries have an arrangement of opting-out of potential donation of organs, a system which it is generally agreed gives rise to a greater availability of organs for transplantation. It is assumed in these countries that all citizens agree to become organ dono s unless they have actively taken steps to indicate that in the relevant circumstances they would $\vec{n} \theta t$ wish to do so. ${ }^{1}$ The policy of assuming consent gives rise to the criticism that those who affe unable or too slow to take the necessary steps to opt-out and who are subsequently candidates for donation may have their organs used in violation of their strongly held wishes. This argument has successfully been used in a number of countres considering a system of opting-out and, as a resuipt of the rejection of opting-out, the supply of mugh needed organs for transplantation has remain sd low. ${ }^{2}$

The availability of organs for transplantation from brain stem dead patients is reduced becauße of an understandable tendency to conservatism $\overrightarrow{\underline{b}} \mathrm{y}$ families in those cases where the prior wishes of their deceased relative are not known. Yet it known that a large majority of persons express a willingness to be postmortem donors ${ }^{3}$ so in mazey cases this caution may be unfounded or may even be in breach of strongly held wishes to donate. Conservatism in these cases often results fromoa reluctance to guess what would have been the choice of the deceased: it is not the case that the families believe that the deceased would hape refused to donate organs, merely that they do net feel comfortable presuming consent. As the burden of decision-making usually falls upon the family without warning, a process of reasoning that helps to infer the wishes of the deceased coufd be a comfort to them.

A family's reluctance to guess the wishes of the deceased may lead it to refuse organ donation. By contrast, when a person's future is under consideration in a medical emergency, relatives do nt hesitate to assert and act on his or her presum\&d desires with some confidence. No caution $\overrightarrow{\mathscr{d}}_{\mathrm{s}}$ exhibited in most cases where an unconsciogs patient is unable to consent to life-extending or enhancing medical intervention. In these cases the presumption is that, absent any indication to the contrary, the patient would consent to the 
treatment. Thus, we assume even without a positive statement to this effect, that a person would consent to undergo invasive surgery in order to prolong his or her life. Potential organ recipients are usually in a position to communicate their willingness to undergo transplantation. ${ }^{4}$ However, if it were the case that the operation that was to be carried out without express consent was an organ transplantation, the patient's best interests would ensure the transplant went ahead.

As a default assumption, it is clear that doctors, transplant managers and families would expect a patient to permit a life-extending or lifeimproving transplant if it was in his or her clinical best interests. So, it is our assumption that most persons would, if their condition required it, be prepared to be recipients of organs. The analogous assumption, that most persons would if the circumstances arose, be prepared to donate organs, does not apparently hold: we are much more cautious about using organs in the absence of any positive evidence that the person had previously been willing to do so.

This asymmetry of inference results from the caution of families of potential donors and a failure to recognise the contingent interdependence of potential recipients and donors. It might be argued that there is no genuine interdependence between donors and recipients, for the donor is never dependent on the recipient and the recipient is totally reliant on the donor for the organ. However, there is a contingent interdependence between all persons prior to any particular person becoming identified as either a potential donor or a prospective recipient. An opting-out system recognises this interdependence. In the absence of a contrary declaration, an opting-out system assumes the consent of a person to donate and, at the same time, gives that person the right to be clinically and morally evaluated on equally favourable terms as any other potential recipients of an organ should he or she need an organ transplant. The recognition that access to potential benefits presupposes a preparedness to contribute gives us the justification for a general presumption of consent to organ donation, while the procedures for opting-out ensure the right to individual exception is protected.

\section{Free-riding}

Those persons who would be prepared to be organ recipients without the corresponding willingness to be organ donors are free-riders in the system, predisposed to benefit without ever consenting to contribute. The decision to opt-out from potential organ donation, if made by someone who would accept an organ transplant, is an overt expression of that individual's preparedness to be a free-rider. While the liberal state and society must allow this position to be held, the free-rider must accept the moral and practical consequences of the position. The practical consequences of opting-out would entail that the person who is a free-rider is liable to be discriminated against in the allocation of organs to recipients.

Resource allocation in medicine is an unavoidable aspect of management in hospitals. The problem is at its most difficult when resources are scarce; or their utilisation is expensive; or the consequences of lack are serious; or all three, as is the case with organ transplantation. ${ }^{5}$ In such cases, where a limited resource must be allocated to someone, it seems reasonable that the free-rider should be penalised for his or her uncharitable views concerning his or her own potential contribution. Free-riding would seem to be possible in other areas of medicine, for example, in blood donation, although the relative availability of blood products makes the application of the concept unnecessary. Free-riding has also raised moral questions in other areas of life, for example non-union members who gain a union-procured pay increase. However, the scarcity of organs for transplantation and the lack of currently viable alternatives such as artificial organs or interspecies donation ${ }^{6}$ make the application of freeriding criteria appropriate in this area.

Doctors are trained in making and balancing clinical judgments, and taking free-riding into account must only be contemplated after it has been established that the situation is clinically neutral ie where there is no medical or surgical advantage to be gained by transplanting into one potential recipient rather than another. Considering whether a patient is a free-rider adds a moral element to the clinical judgment of the doctor, the result of which may be the withholding of treatment from that individual. This would seem to be in contravention of standard medical ethics that seek to exclude moral judgments such as "desert" from clinical decisions and almost certainly doctors would be reluctant to take sole responsibility for such ethically grounded decisions. However, in cases where a resource is extremely limited, it is sometimes appropriate for moral criteria, such as free-riding, to be used to differentiate between patients.

It might be thought that there would be a dilemma when the probability of the success of a transplant into a person who had been predisposed to donate, the "generous recipient", is low while the likelihood of a successful outcome for the person who has opted-out of donation, the 
"selfish recipient", ${ }^{7}$ is high. In all cases it is the clinical decision that must take priority on utilitarian grounds, as presenting less chance of the resource being wasted in an adverse clinical outcome such as organ rejection. In these cases, where the "selfish recipient" would benefit over the "generous recipient", the priority of the clinical judgment over the moral judgment might seem to undermine the point of using the concept of free-riding in the first place. Of course, the priority of the clinical over the moral may mean that in practice there is seldom or never a disadvantage as a consequence of free-riding. But the value of the concept of "free-riding" lies less in its application by doctors to specific cases than in the political possibilities it brings forward. Its usefulness lies in the fact that it promotes a discourse which leads to a greater acceptance of the presumption of consent and it may also make decisions easier for families of potential donors.

\section{Essential interdependence}

If it is agreed that most people would consent to benefiting from transplant technology and that free-riding is a morally precarious position to hold, it is possible to arouse people's awareness to the moral consequences of the stance which they are taking when they choose to opt-out. Where people still choose to opt-out knowing that this constitutes free-riding, they should be made aware that they may be disadvantaged in the future if they should ever become potential recipients of organs. ${ }^{8}$ Such disadvantage counterbalances the unfairness of free-riding and since the decision as to who receives an organ will be clinically neutral, there can be no utilitarian argument against the application of the free-riding criterion. The organ to be transplanted goes, other things being equal, to the person who has not declined to donate organs him/herself. How many people would be content to be free-riders when the question of organ donation is put in these terms is not known. What is likely, however, is that once made explicit the concept of "free-riding" will stimulate discussion and bring the essential interdependence of potential organ recipients and donors to the forefront of public debates on organ donation.

The person who chooses to opt-out must consider his or her willingness to be a recipient of an organ, and must recognise the inevitable consequence that any willingness entails, that of free-riding. Publicity that promotes the idea that an opted-out person may be less likely to receive a transplant if he or she ever needs one, forces opters-out to reconsider their own moral standards. It is hoped that the unease that will be felt when opting-out is acknowledged as being a form of free-riding will have the consequence that fet people will choose to opt-out. As well, knowledôge of the moral and practical consequences for someone who chooses to opt-out of organ donation while not wanting to exclude him/herseff from the benefit of a future transplant can be useg to neutralise the difficulties of consent that appe to hinder the straightforward acceptance of opting-out systems. Where a person has not maêpe a declaration stating that he or she wishes to optoout, and where it is believed that he or she wouta not have refused the benefits of transplant technology for him or herself, it can safely assumed that he or she would have consented fo be a donor, given the charitable - and not unreasonable - assumption that this person is not:a free-rider. Given this assumption, and the obligs tions which result from being a member of a corgmunity of interdependent potential donors and recipients, a decision that infers the consent that person to donate organs is possible.

As well as deterring potential opters-out, widegr knowledge of the concept of free-riding resolves some of the difficulties that families face when making decisions on behalf of their deceased relatives. The use of free-riding makes clear the links between the instinct to be charitable ie donate, and a broader picture which includesष్ default assumption of self preservation, ie receive. Thus, families who accept that theुr prematurely dead would have wished to continue living, and who believe that their relative was noța free-rider, might be satisfied that their relative would have consented to organ donation as part $\mathrm{d}$ this broader web of rights, duties, obligations a fairness. Similarly, in cases where a person woutd have been unable to make decisions due to youth incompetence, the default assumption is that he or she would take an opportunity to improve amd extend his or her life through transplantation if this were necessary, that he or she was not a free-ridef, and therefore would not have chosen to opt-out.

Conceivably, it is a violation of the principle rof consent to assume without evidence an altruistre motive to donate organs. It is not a violation of the principle of consent to pre-suppose self-interęst, nor is it a violation of medical ethics to combinge the concept of self-interest with concepts of interdependence and obligation. A system which relies on publicising the disadvantages that may incurred by free-riders in order to increase the supply of potential donors demonstrates that teitly agreeing to organ donation is, in part, an acteff self-interest. The system must also have a defawlt assumption that its citizens are not free-rideos. This assumption can be made on at least three grounds: the empirical evidence of support 
organ donation; the expectation that most people would naturally wish to avoid the disadvantages that might accrue from opting-out, and the conviction that many citizens recognise the mutual interdependence of themselves and their fellow citizens to be particularly close in the case of organ donation and as a result they are happy to accept their duty to be potential donors. If we accept these assumptions then we should be able to support the introduction of an opting-out system.

The conjunction of tacit consent with a free-riding rationale must be used with caution. It is not difficult to see how this argument could be extended to the use of other body parts in research or treatment. It is important to stress that the free-riding distinction should only be used in situations that are clinically neutral and that its principal function is in the political arena, in making clear the interdependence of all persons as potential organ donors or organ recipients. Awareness of free-riding forces "selfish" opters-out to recognise the consequences of their choice; moral impropriety and the possibility of disadvantage, should the situation of their own need ever arise.

\section{Prior volunteers only - Jarvis's modest proposal}

A comparable proposal to increase the availability of organs by appealing to self-interest and penalising those who withhold consent to postmortem donation was made recently by Jarvis. ${ }^{9}$ He puts forward what he terms a "modest proposal" that advocates the rationing of organs by limiting transplantation to those who had previously consented to be donors themselves should the situation arise. Put negatively, those who do not opt-in to potential donation on the Jarvis scheme are disqualified from the possibility of a transplant or placed behind those who have opted-in. ${ }^{10}$ As has been noted by Gillon, ${ }^{11}$ this proposal blocks an individual's access to a particular treatment on the basis of assumed moral blameworthiness. This is a particularly harsh and final punishment for what may, in many cases, be inaction rather than a considered decision never to donate. Given the very low probability that an individual will become a candidate either for donation or receipt of organs, opting-in can hardly be seen as compelling or urgent, especially for young, healthy people. The Jarvis proposal creates the opposite problem to that of opting-out systems, ie how could one ever know that a person had really chosen to reject potential donation rather than been merely negligent? Although opting-in to potential donation (with the consequence that one also opts-in to potential receipt) seems like a one-off insurance policy with no (or an insubstantial) premium, it is arguable whether the take-up of this type of insurance will be all that much higher than is the carrying of donor cards at the present time.

As Jarvis accepts, the proposal encounters other problems, such as obtaining the consent of children and the inadequately autonomous. He suggests excluding these groups from the scheme, thereby leaving unresolved a significant practical problem concerning the transplantation of organs into children who, because of their size, can often only utilise organs donated by other children. As Gillon notes, there are ways to overcome this problem: registration of consent by parents of young children, and allowing health workers and others to make decisions on behalf of mentally impaired people. $^{12}$ However, as Gillon's suggestion illustrates, accurately to register the entire population of potential organ donors (which would surely be impossible anyway) the Jarvis proposal would require a large bureaucratic structure to administer it. This would hardly seem cost-effective when viewed against the comparatively small number of persons who are candidates for organ donation each year. In addition, as organs are not uncommonly transported long distances for transplantation into suitable recipients, the exercise would have to cover all those countries that share data and collaborate in the matching of recipients with available organs. In this respect at least, the Jarvis proposal is far from "modest".

Instead of a complicated and expensive registration scheme, it is much more efficient to involve only those persons for whom organ donation is an issue, ie the families of brain stem dead patients. The Jarvis proposal is averse to the current practice of asking families for their consent. Presumably, on the Jarvis scheme doctors would have to forgo the removal of organs in those cases where the deceased had not opted-in, even when the families know that the deceased would have consented. It is known that there are wide variations in the response of the general public to low-probability risk. ${ }^{13}$ If, as seems possible given current opting-in schemes, there is a low level of registration, the presumption that this failure to opt-in represents strongly held wishes not to donate may in fact have an effect contrary to that which Jarvis intends, ie a reduction in the number of available organs. With no scope for a decision to be taken by the family of the deceased this could effectively reduce the potential donor population rather than increase it.

However, the most unsatisfactory consequence of the Jarvis proposal would be the wastage of organs as a result of the ineligibility of a suitable 
recipient. The Jarvis proposal assumes that the matching of organs and donors is straightforward but, unfortunately, this is rarely the case. Not every organ that becomes available suits the needs of several potential recipients, and the Jarvis proposal, which has the consequence of excluding suitable potential recipients from the list of those eligible to receive an organ, runs the risk of wasting the very resource the availability of which he is trying to increase. This proposal may increase the numbers of those who have made clear their willingness to donate organs in the event of their death but it has the effect of reducing the demand for donor organs artificially, by excluding certain people from the pool of potential recipients, and possibly wasting organs as a result. Even in the less extreme version of Jarvis's proposal, where those who have not opted-in are placed at the end of the queue, time constraints in the matching and transportation of organs make this procedure unnecessarily risky.

The moral element in transplant decisions cannot be denied. Decisions about rationing and the quality of a person's life are increasingly a part of modern medical practice, for example in the refusal to operate on a cigarette smoker or the decision not to administer life-extending treatment to a profoundly ill neonate. Decisions that are justified on the basis of clinical outcome may disguise an underlying ethical determination of the most worthy patient as well as a utilitarian calculation as to the best use of resources. So, the potential for the moral as well as clinical ordering of potential transplant recipients, however difficult, must be acknowledged. Unfortunately, the Jarvis proposal fails to provide a method for safely discriminating on moral grounds and presents serious practical problems in its implementation.

\section{Conclusion}

A system of opting-out is the most efficient form of obtaining consent for the use of organs in transplantation. The obstacle of tacit consent is reduced by the belief that the majority of people would wish to benefit from the technology if they needed it and are not free-riders. As a result, a donor's prior wishes cannot be violated by the donation of his or her organs unless it is known that he or she would not have wished to receive (or donate) organs; or if he or she was known to be a free-rider with respect to transplantation and to understand the potentially detrimental consequences of this position.
In order to secure consent, families must satisfied that their deceased relative would hase taken the decision to donate. Families should comforted by the knowledge that it is both empirically and morally likely that the deceased would have chosen to donate organs. Reachi僁 this conclusion is made easier for the familes within an opting-out system where the deceased has given no evidence of a reluctance to donate, and where it is agreed that the deceased was nota free-rider. Such a system provides a minimalty administered means of enabling the relatives \&f brain stem dead patients to take decisions donate on behalf of their deceased and $\overrightarrow{B e}_{e}$ confident in those decisions.

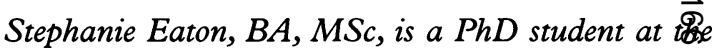
Centre for Law and Society, University of Edinburgh, Edinburgh.

\section{References}

1 In practice many countries with opting-out systems still seekg obtain the authorisation of relatives for the use of organs of transplantation. See Haag BW, Stuart FP. The organ donor: brain death, selection criteria, supply and demand. In: Flye MW, ed. Principles of organ transplantation. Philadelphia: W Saunders Company, 1989: 185.

2 See Kittur DS, Hogan MM, Thukral VK, McGaw हु Alexander JW. Incentives for organ donation? Lancet 1991;388: 1441 who report that organ donation in Belgium has increasid by $119 \%$ in the three years since opting-out legislation introduced.

3 West R. Organ transplantation. London: Office of Hea Economics, 1991:10.

4 For altruistic reasons some potential recipients may prefer to see donated organs go to younger people or to those with dependants and there are, of course, some religious groups who do not accept transplantation.

5 Although transplantation is obviously an expensive medical treatment, it has been noted that over a period of some years, renal transplantation is more economical than continued diatysis. See also reference 3: 25 .

6 The presumed consent implicit in opting-out systems may atso facilitate the speedier recovery of organs from deceased perso?s, reducing the demand for elective ventilation of cadavers with the additional ethical doubts that this procedure raises.

7 The use of the terms "generous" and "selfish" are of course value-laden, and oversimplify the motives behind a decisionteo donate or to refrain from donation. These terms are intended here as a shorthand and to give the flavour of the moral argument.

8 In the hypothetical case of someone who has opted-out and then becomes aware that he/she needs a transplant it is, of coufse, possible for that person to "change his/her mind" but \$ुe changed circumstances will leave some doubt as to the aetiology of the decision. In any case, publicity of such cases may servoto discourage other potential opters-out.

9 Jarvis R. Join the club: a modest proposal to increase availabsqty of donor organs. Fournal of Medical Ethics 1995;21:199-204.

10 Only free-riders would be penalised on the perfectly imporemented Jarvis proposal as those who refused to donate on, for example religious grounds, would presumably also refuse ఛo accept organs in transplantation.

11 Gillon R. On giving preference to prior volunteers when alloक्षgting organs for transplant [editorial]. Fournal of Medical Et hics 1995;21:195-6.

12 See Reference 11: 195.

13 Adams J. Risk. London: University College London Press, 1925. 